\title{
Analisis Geometri pada Perancangan Fasilitas Duduk: Sebuah Aplikasi
}

\author{
Hertina Susandari dan Taufik Hidayat \\ Departemen Desain Produk Industri, Fakultas Arsitektur Desain dan Perencanaan, \\ Institut Teknologi Sepuluh Nopember \\ e-mail: susan@prodes.its.ac.id
}

\begin{abstract}
Abstrak - Hingga saat ini analisis geometri diyakini masih relevan digunakan untuk menciptakan karya atau produk yang berkualitas secara visual. Tetapi aspek visual juga harus berkompromi dengan aspek yang lainnya agar menghasilkan produk yang optimal. Artikel ini akan mengkompromilan analisis geometri dengan aspek antropometri duduk pada produk kursi makan dan kursi teras/ santai. Belum ada panduan yang ketat untuk melakukan analisis geometri menjadikan tantangan tersendiri untuk diselesaikan. Hasil akhir yang didapatkan selain panduan analisis geometri adalah dua alternatif rekomendasi geometri dari kursi balero silang dan kursi minimalis.
\end{abstract}

Kata Kunci: analisis geometri, antropometri duduk, geometri kursi, golden rectangle, root rectangle

Abstract - Currently, Geometric analysis is one of relevant technical to create high quality visual product. In the other hand, visual aspect must be compromised with other design aspect to produce optimum product. This article will explain dining chair and patio chair that applied compromised geometry analysis towards seat anthropometry. The challenge for using geometry analysis is more about less strict guidance available for it. The result from this process is guidance for geometry analysis, and also two alternatives geometry based recommendation for Balero Silang Chair and Minimalistic Chair.

Keywords: geometric analysis, anthropometric sitting, geometry of chair, golden rectangle, root rectangle

\section{PENDAHULUAN}

\section{A. Latar Belakang}

Aspek visual merupakan aspek utama dalam sebuah produk atau karya, tetapi juga penting untuk digaris bawahi bahwa aspek visualpun perlu berkompromi dengan aspek yang lainnya, seperti: aspek fungsi, aspek informasi, dan aspekaspek lainnya [1]. Telah diyakini sejak jaman Yunani, bahwa untuk menciptakan produk atau karya dengan visual yang berkualitas adalah dengan menggunakan analisis geometri, baik menggunakan golden ratio ataupun root ratio. Bahkan hingga saat ini metode ini juga masih digunakan pada penciptaan visual produk-produk modern, seperti desain mobil VW Beetle (1997) yang menggunakan golden ellips [2], mobil SSangyong New-Korando, dan kulkas Kim-chi yang menggunakan root 2 [3]. Beberapa riset juga masih mengangkat isu mengenai proporsi yang memberikan impresi positif bagi konsumer, contohnya: desain produk vacuum cleaner [4]. Ada juga riset yang melakukan evaluasi geometri terhadap kursi zig zag dan kursi $L C Z$ dengan menggunakan geometri tubuh manusia (antropometri). Tetapi belum ada artikel yang membahas dengan detil mengenai aspek geometri yang kompromis dengan aspek lainnya.

Sentra IKM mebel Bukir, Pasuruan telah lama dikenal sebagai salah satu produsen mebel di Jawa Timur. Desain mebel yang dihasilkan banyak terinspirasi dari mebel gaya eropa ada juga yang dikembangkan sedikit sesuai dengan kapasitas desain dan geometri kursi ala IKM. Hal inilah yang menjadikan produk mebel Pasuruan menarik untuk dikembangkan atau didesain ulang, salah satunya dengan metode analisis geometri. Dari sekian banyak jenis produk, penelitian Hidayat, dkk, 2009, memfokuskan pada kursi berjenis dudukan tunggal yang memiliki desain sudah dikembangkan oleh perajin IKM. Ada 18 varian kursi terpilih untuk didesain ulang [5].

Artikel ini akan mengisi ceruk aspek geometri dan aspek manusia (antropometri) pada benda produk, dengan mengambil contoh kasus kursi dari penelitian sebelumnya.

\section{B. Permasalahan}

Tidak ada panduan yang ketat dalam melakukan analisis geometri, hanya serangkaian komposisi yang dikembangkan dan digunakan selama berabad-abad[2]. Pernyataan ini dapat menjadi sebuah permasalahan, karena tidak ada langkah pasti bagaimana memulai analisis geometri dan bagaimana cara mengkompromikannya dengan antropometri posisi duduk. Namun di satu sisi juga dapat diartikan memberikan kebebasan bagi penulis untuk melakukan eksplorasi seluasluasnya.

\section{Batasan Masalah}

1. Kursi berjenis dudukan tunggal, meliputi :

- kursi makan tanpa sandaran lengan, yaitu: kursi balero silang

- kursi teras/ tamu dengan sandaran lengan, yaitu: kursi minimalis 
2. Hanya memperbaiki geometri kursi, tidak melakukan perbaikan bentuk secara mendalam.

\section{Tujuan}

1. Mendapatkan rekomendasi visual dari hasil kompromi antara analisis geometri dan antropometri posisi duduk.

2. Meningkatkan kualitas visual pada desain fasilitas duduk yang dikembangkan oleh perajin IKM

\section{METODE PENELITIAN}

Gambar 1 menerangkan alur penyelesaian masalah dari artikel ini. Secara garis besar metode penelitian yang akan digunakan adalah studi literatur dan melakukan eksperimen pada software.

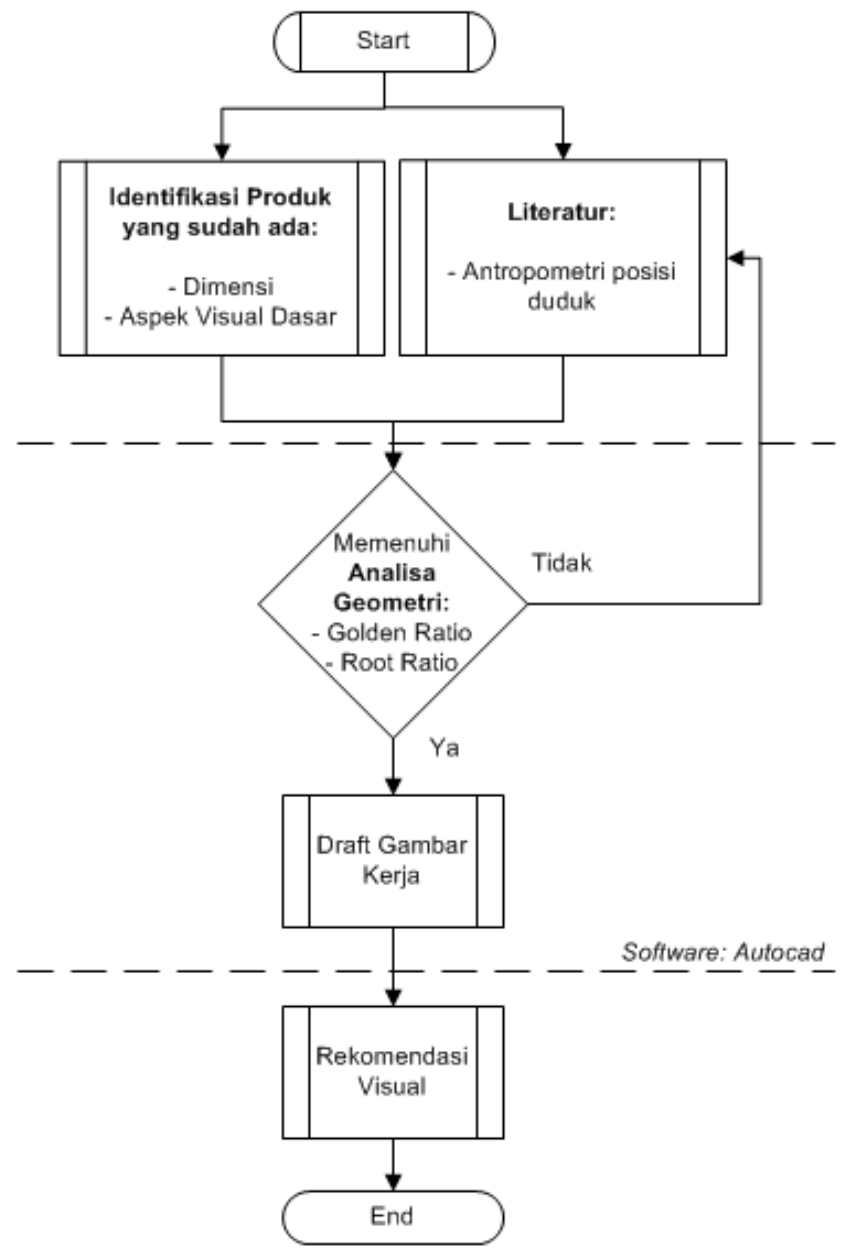

Gambar. 1. Alur metode penelitian

\section{Identifikasi eksisting}

Pada tahap ini, dilakukan identifikasi secara detil pada kursi eksisting. Langkah awal yang dilakukan adalah melakukan pengukuran ulang dari kursi balero silang dan kursi minimalis. Pengukuran dilakukan pada titik kritis perancangan kursi, yaitu: tinggi dudukan kursi, lebar kursi, kedalaman kursi, sudut sandaran kursi, tinggi sandaran kursi dan tinggi sandaran lengan. Selanjutnya, dengan berbekal pengalaman dan pengetahuan terhadap dasar desain maka dilakukan evaluasi pada aspek visual yang mendasar, yaitu: kesatuan (unity).

\section{Studi Literatur}

Studi literatur dibagi menjadi dua, yaitu (1) untuk mendapatkan data antropometri dan (2) untuk memperkaya ragam analisis geometri. Tujuan dari studi literatur antropometri di sini adalah untuk mendapatkan acuan ukuran antropometri posisi duduk yang benar. Walaupun memang sebuah kursi dengan pendekatan antropometri yang tepat belum tentu nyaman, tetapi telah disepakati bahwa sebuah kursi harus didasarkan pada data antropometri yang terpilih dengan tepat[6]. Sedangkan tujuan yang kedua adalah, untuk mendapatkan jenis analisis geometri sebanyak-banyaknya.

\section{Analisis Geometri}

Setelah data kursi eksisting dan data literatur dianalisis, berikutnya adalah melakukan analisis geometri yang dibantu dengan software Auto CAD. Tahapan ini banyak dilakukan eksperimen pada ukuran ideal kursi dengan jenis geometri mana yang cocok dengan karakter kursi. Apabila telah ditemukan ukuran yang kompromistis maka dapat dilanjutkan pada tahap selanjutnya.

\section{Draft gambar kerja}

Agar hasil analisis geometri terbaca dengan baik, maka diperlukan gambar lebih detil beserta ukurannya. Oleh karena tujuan artikel ini tidak sampai pada tahap produksi, maka gambar kerja sifatnya cukup sampai draft saja.

Pada akhirnya dari gambar tersebut perlu diterjemahkan secara verbal agar rekomendasi visual yang kompromis dapat dipahami oleh pembaca.

\section{HASIL DAN PEMBAHASAN}

\section{a. Kursi balero silang}

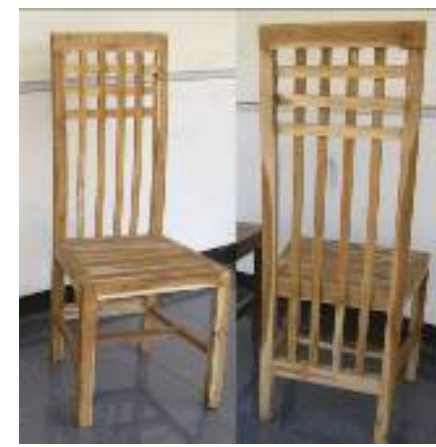

Gambar. 2. Eksisting kursi Balero Silang [5]

Pada dasarnya, kursi Balero Silang merupakan pengembangan dari kursi Balero, yang memiliki karakteristik sandaran kursi 
tinggi dari bilah-bilah kayu berpenampang persegi yang disusun secara vertikal. Disebut Balero Silang karena pada bagian atas sandarannya ditambahkan tiga buah bilah kayu yang disusun secara horizontal seperti yang ditunjukkan pada Gambar 2.

Hasil pengukuran pada produk eksisting dan ukuran yang direkomendasikan ditunjukkan pada Tabel 1 [6][7], dari tabel perbandingan ternyata ada beberapa dimensi pada produk eksisting perlu dilakukan penyesuaian, yaitu: tinggi dudukan perlu dibuat lebih tinggi, lebar dudukan belakang perlu ditambah agar sesuai dengan ukuran panggul pengguna, serta tinggi sandaran kursi perlu disesuaikan tidak hanya untuk faktor geometri saja tetapi juga untuk pertimbangan keseimbangan kursi.

Tabel 1. Data pengukuran produk eksisting kursi Balero Silang dan referensi (dalam millimeter)

\begin{tabular}{l|c|c}
\hline \multicolumn{1}{c|}{ Titik kritis } & Produk Eksisting & $\begin{array}{c}\text { Dimensi acuan kursi } \\
\text { makan }\end{array}$ \\
\hline Tinggi dudukan & 410 & 420 \\
\hline Lebar dudukan & $450-380$ & $432-483$ atau $\geq 405$ \\
\hline Kedalaman kursi & 410 & $394-406$ \\
\hline Kemiringan sudut sandaran & $92^{0}$ & $90^{0}-95^{0}$ \\
\hline Tinggi sandaran punggung & 670 & $432-610$ \\
\hline
\end{tabular}

Analisis geometri dilakukan dengan cara melakukan eksperimen pada software AutoCAD. Langkah pertama adalah memutuskan menggunakan jenis geometri yang mana. Melihat karakter kursi yang ramping, tinggi serta persyaratan desain sebelumnya, maka yang cocok adalah menggunakan geometri root 5 dengan persegi awal berukuran $460 \times 460$, seperti yang ditunjukkan pada gambar $3 a$.

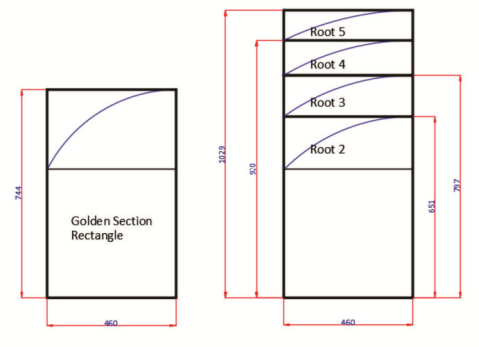

a.

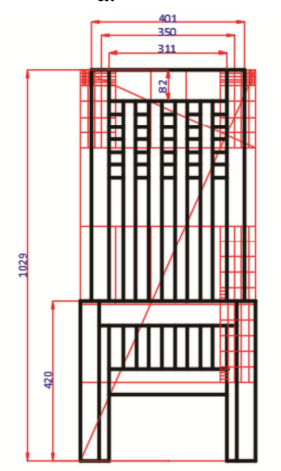

c.

Gambar. 3. (a) Eksplorasi geometri yang sesuai dengan ukuran kursi Balero Silang; (b) Root 5 hingga pembagian jaring-jaring terkecil, (c) aplikasi analisis geometri pada kursi Balero Silang
Gambar 3 mengilustrasikan langkah kedua, yaitu membagi persegi panjang menjadi lima, hingga lima persegi panjang terkeci pada ketiga gambar tampak. Setelah jaring jaring terkecil selesai dibuat, saatnya untuk menempatkan bagian kursi sesuai dengan ukuran dan jarring-jaring.
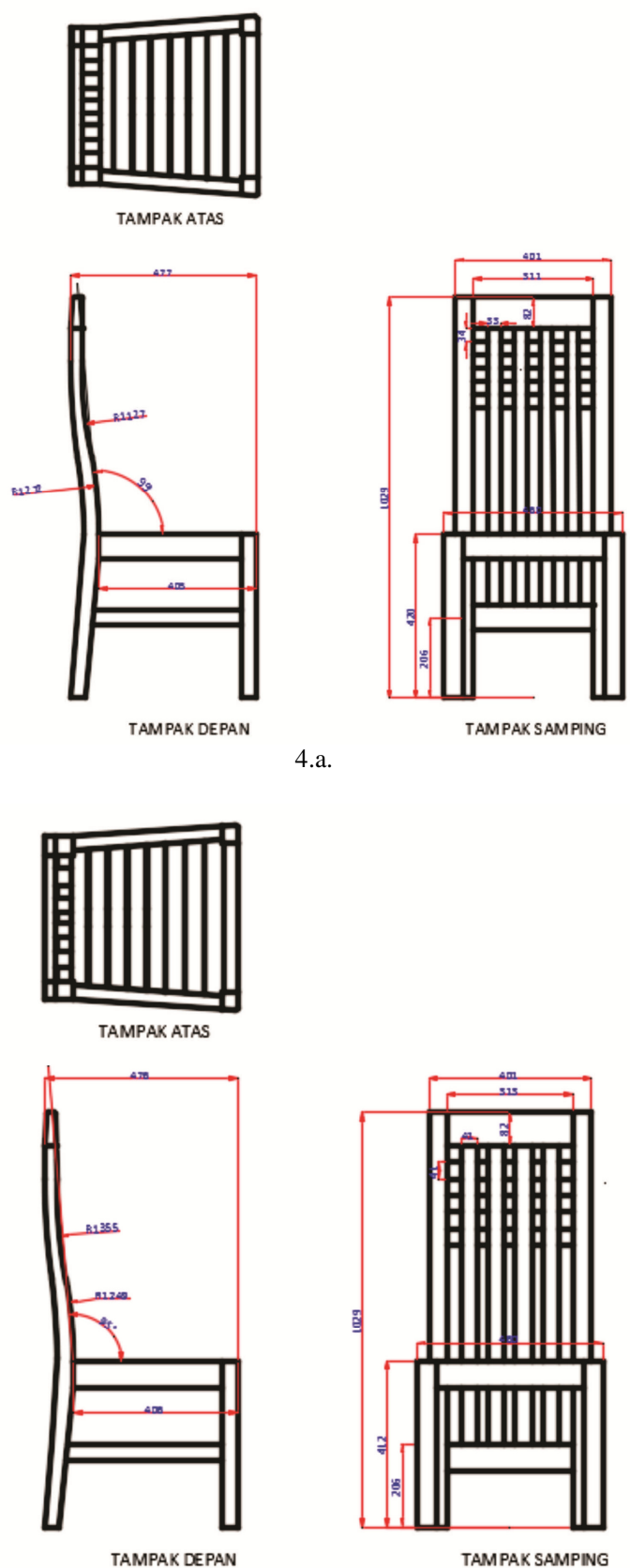

4.b.

Gambar. 4. Draft gambar kerja dari dua alternatif geometri kursi Balero Silang

Contoh:

- tinggi dudukan yang disyaratkan adalah $420 \mathrm{~mm}$, maka untuk mendapatkan dimensi tinggi dudukan yang baru dicari dengan cara membagi persegi panjang root 5 hingga jaringjaring terkecil seperti ditunjukkan pada gambar $3 \mathrm{c}$. 
ukuran diameter melengkung pada sandaran kursi adalah dari panjang diagonal persegi panjang root 5 yang telah disesuaikan, dll.

Dengan batasan permasalahan tidak mengubah ukuran penggunaan kayu dan karakteristik kursi, maka diperoleh dua alternatif geometri baru dari kursi Balero Silang. Alternatif pertama seperti yang ditunjukkan pada Gambar 4, menghasilkan: (1) tinggi dudukan ditempatkan sesuai dengan ukuran acuan dan jaring-jaring terkecil, yaitu $420 \mathrm{~mm}$. (2) bagian bawah sandaran kursi dan struktur penguat kaki ditempatkan tepat di tengah garis bagi root 5, (3) ukuran bilahbilah pada sandaran kursi didapatkan dari ukuran jaring-jaring root 5, yaitu $33 \mathrm{~mm}$. Sedangkan pada alternatif kedua (Gambar 4b): (1) geometri yang berbeda ditawarkan pada ketinggian dudukan yang diambil dari jaring-jaring root 5 , yaitu $412 \mathrm{~mm}$, (2) bagian bawah sandaran kursi berhenti tepat pada garis jaring-jaring, $206 \mathrm{~mm}$ dari garis tanah, (3) penyusunan bilah-bilah horizontal disesuaikan menurut pembagian jaring-jaring kecil root5, yaitu berjarak $41 \mathrm{~mm}$.

\section{b. Kursi Minimalis}

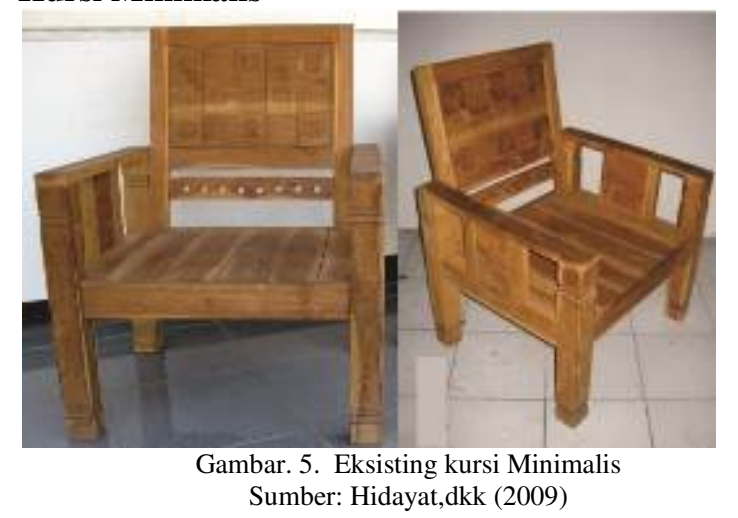

Kursi minimalis merupakan pengembangan desain dari kursi dengan impresi berat dan penuh ukiran, yang disesuaikan dengan tren minimalis saat ini. Kesan berat direduksi dengan cara menggunakan ukuran balok kayu yang lebih kecil, sedangkan kesan ukiran yang rumit dibuat lebih sederhana dengan motif geometris dasar, yaitu: motif spiral dan garisgaris horizontal seperti pada Gambar 5.

Tabel 2. Data pengukuran produk eksisting kursi minimlis dan referensi (dalam millimeter)

\begin{tabular}{l|c|c}
\hline \multicolumn{1}{c|}{ Titik kritis } & Produk Eksisting & $\begin{array}{c}\text { Dimensi acuan kursi } \\
\text { santai/ teras }\end{array}$ \\
\hline Tinggi dudukan & 355 & $356-508$ \\
\hline Lebar dudukan & 555 & $457-508$ \\
\hline Kedalaman kursi & 520 & $419-445$ \\
\hline Kemiringan sudut sandaran & $101^{0}$ & $\geq 105^{0}$ \\
\hline Tinggi sandaran punggung & 540 & $432-610$ \\
\hline Tinggi sandaran lengan & 222 & $178-254$ \\
\hline
\end{tabular}

Sebagian besar dimensi kritis pada kursi eksisting masih masuk pada rentang yang disyaratkan oleh acuan, kecuali pada dimensi lebar dudukan yang ternyata lebih panjang dari batas atas acuan dan sudut sandaran kursi yang kurang besar bagi jenis kursi tamu/teras. Khusus untuk perancangan kursi tamu/ teras, kemiringan tidak hanya diperuntukkan pada sandaran saja tetapi juga dapat dilakukan pada tinggi dudukan dengan sudut kemiringan paling besar adalah $5^{\circ}$.

Ukuran persegi 508×508 mm berasal dari batas atas dimensi lebar dudukan. Proses selanjutnya adalah menemukan geometri persegi panjang yang sesuai dengan karakter kursi Minimalis. Hasil eksplorasi dan eksperimen ukuran geometri persegi panjang diperoleh tiga alternatif, yaitu: berbasis golden rectangle, root 2 dan root 3 seperti yang digambarkan pada Gambar 6.
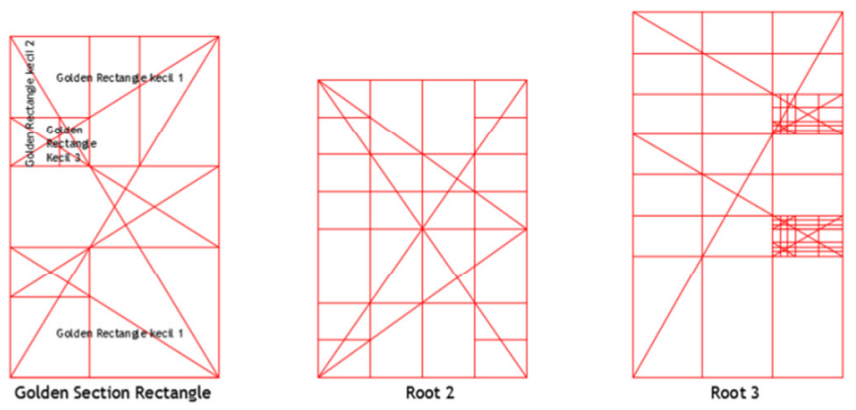

Gambar. 6. Geometri dan pembagian jaring-jaring pada Golden Rectangle dan Root

Persegi panjang ini kemudian dibagi menjadi jaring-jaring sesuai dengan ketentuan. Ternyata pembagian jaring-jaring pada persegi panjang dari golden rectangle dengan root cukup berbeda, sehingga pembahasan alternatif akan dijelaskan satu persatu.

\section{Alternatif geometri berbasis golden rectangle}
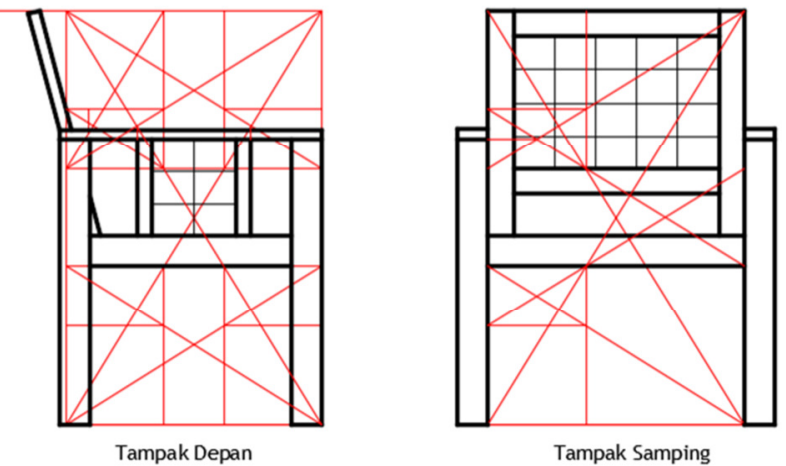

Gambar. 7. Proses pencarian geometri kursi Minimalis menggunakan Golden Rectangle

Cara termudah untuk memulai analisis geometri adalah menetapkan lebar kursi dari tampak samping. Kemudian, secara berurutan menentukan letak tinggi dudukan, tinggi sandaran lengan dan tinggi sandaran kursi. Tinggi tempat duduk diperoleh dari golden rectangle kecil 1. Sandaran lengan ditemukan dari pertemuan garis diagonal golden rectangle kecil 1 dengan diagonal golden rectangle kecil 3. 
Sedangkan bagian bawah sandaran mengikuti garis golden rectangle kecil 1. Penentuan kedalaman kursi dan kemiringan sandaran, didapatkan dari tampak depan seperti yang diperlihatkan pada Gambar 7, tampak bahwa garis sandaran dibawa hingga melewati titik golden rectangle kecil 2. Begitupula dalam menempatkan elemen estetis pada sandaran lengan berasal dari pertemuan antara garis diagonal besar persegi panjang dengan diagonal golden rectangle kecil 1.

\section{Alternatif geometri berbasis root 3}

Geometri kursi yang dihasilkan dari root 2 ternyata kurang memenuhi persyaratan, karena hanya mendapatkan tinggi sandaran sebesar $359 \mathrm{~mm}$ sedangkan syarat minimumnya adalah $432 \mathrm{~mm}$. Sehingga, alternatif geometri dari root 2 diabaikan.

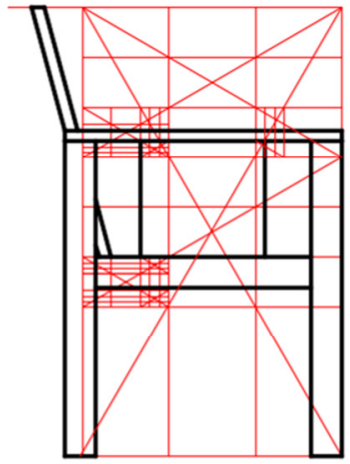

Tampak Depan

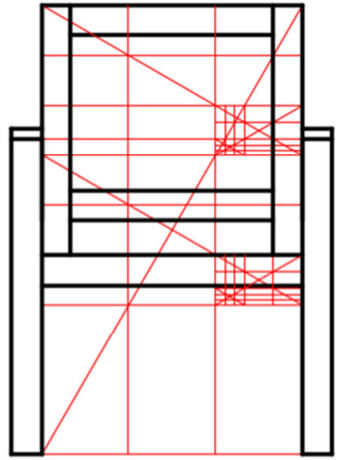

Tampak Samping
Gambar. 8. Proses pencarian geometri kursi Minimalis menggunakan Root 3

Pada geometri root 3, ketinggian dudukan diperoleh dari 4/9 tinggi persegi panjang dan satu tingkat di atasnya (5/9) adalah bagian bawah sandaran dudukan. Untuk mendapatkan tinggi sandaran lengan, kedalaman kursi dan penempatan elemen estetis sandaran lengan ternyata dibutuhkan pembagian persegi panjang yang lebih kecil lagi, yaitu persegi panjang kecil ke-3 seperti yang diperlihatkan pada Gambar 8. Jika dirangkum, dimensi kedua alternaif ini dapat dilihat pada Tabel 3.

Tabel 3. Alternatif geometri kursi Minimalis (dalam millimeter)

\begin{tabular}{l|c|c|c}
\hline \multicolumn{1}{c|}{ Titik kritis } & Acuan & $\begin{array}{c}\text { Golden } \\
\text { Rectangle }\end{array}$ & Root 3 \\
\hline Tinggi dudukan & $356-508$ & 374 & 391 \\
\hline Tinggi sandaran lengan & $178-254$ & 216 & 248 \\
\hline Tinggi sandaran punggung & $432-610$ & 448 & 489 \\
\hline Kedalaman kursi & $419-445$ & 440 & 452 \\
\hline
\end{tabular}

\section{KESIMPULAN}

Permasalahan yang diangkat pada artikel ini adalah tentang tidak adanya panduan yang tepat untuk melakukan analisis geometri, namun dari dua contoh kasus kursi tesebut dapat disimpulkan salah satu cara untuk menggunakan analisis geometri adalah sebagai berikut:
1. Temukan persayaratan anropometri kursi yang sesuai. Telah kita ketahui bahwa ternyata dimensi kursi makan dan kursi santai berbeda. Sehingga tidak menutup kemungkinan ada perbedaan yang signifikan pada jenis kursi atau produk yang lain.

2. Gunakan sisi kursi yang paling lebar untuk menemukan ukuran dasar persegi, dalam contoh ini adalah bagian lebar kursi.

3. Perhatikan karakteristik fisik kursi, jika memiliki bentuk yang ramping dan tinggi dapat dipastikan akan menggunakan root 3 ke atas, jika memiliki karakteristik bentuk yang hampir seimbang antara perbandingan lebar dan tinggi kemungkinan yang digunakan golden rectangle atau root 3 (pebedaan dua geometri ini cukup tipis). Tetapi yang penting adalah segera eksekusi menggunakan gambar untuk mengetahuinya secara pasti.

4. Bagi persegi panjang tadi sesuai dengan karakter geometri. Misal: bila menggunakan root 5, maka bagi panjang menjadi lima sama besar, dst. Pembagian ini juga dibutuhkan kreativitas.

5. Temukan titik kritis perancangan kursi dari garis-garis bagi persegi panjang.

Tentunya cara di atas hanya salah satu cara melakukan analisis geometri saja, masih banyak cara lain yang perlu digali. Begiu juga desain kursi yang dihasilkan pada artikel ini masih perlu divalidasi dan diuji kebenarannya.

\section{DAFTAR PUSTAKA}

[1] Masri, Andry, 2010, Strategi Visual - "Bermain dengan Formalistik dan Semiotik untuk Menghasilkan Kualitas Visual dalam Desain”, Jalasutra, Jogjakarta.

[2] Elam, Kimberly, 2011, "Geometry of Design - Studies in Proportion and Composition", $2^{\text {nd }}$ Edition, Princeton Architectural Press, New York.

[3] Jung, Joo Young, Zahn, Nico dan Badke-Schaub, Petra, 20011, "Comparison Between Rectangular Proportions: Golden versus Root Ratio", Proceedings of IASDR2011, The $4^{\text {th }}$ World Conference on Design Research, Delf, Netherlands.

[4] Avramovic, Darko, Vladic, Gojko, Kasikovic, Nemanja, dan Ivan, Pincjer, 2013, Aplicability of Golden Ratio Rule in Modern Product Design, "Journal of Graphic Engineering and Design", Vol 4 (1), pp. 29 -35 .

[5] Hidayat, Taufik, Indraprasti, Anggri, dan Susandari, Hertina, 2009, "Standarisasi dan Pengembangan Desain pada Produk Pengrajin Mebel di Jawa Timur", Laporan Akhir Hibah Kompetitif Penelitian Sesuai Prioritas Nasional -Lembaga Penelitian dan Pengabdian kepada Masyarakat - ITS, Surabaya.

[6] Panero, Julius dan Zelnik, Martin, 1979, Dimensi Manusia dan Ruang Interior, Penerbit Erlangga, Jakarta.

[7] Tilley, Alvin R, 1993, The Measure of Man and Woman - Human Factors in Design, Watson-Guptill Publications, New York 